\title{
Gebelikte Adneksiyel Kitleye Yaklaşım: Olgu Sunumu ve Derleme
}

Management of Adnexial Mass in Pregnancy: Case Report and Review

\section{Elif MEŞECI *, Semra Kayataş ESER **, Cem ÖNCÜLOĞLU *, Fuat DEMİRKIRAN ***}

(*) Acıbadem Kozyatağı Hastanesi, İstanbul, Türkiye.

$\left({ }^{* *}\right)$ Zeynep Kamil Kadın ve Çocuk Hastalıkları Eğitim ve Araştırma Hastanesi, İstanbul, Türkiye.

$\left.{ }^{(* *}\right)$ İstanbul Ünv. Cerrahpaşa Tıp Fak., Kadın Hast. ve Doğum Anabilim Dalı, Jink. Onkoloji BI., İstanbul, Türkiye.

\section{$\ddot{O Z Z T T}$}

Konservatif takipten komplike operasyonlara kadar geniş bir spektrumda tedavi gerektiren gebelikteki adneksiyel kitlelere yaklaşımda belirlenmiş bir konsesusu yoktur. Siklikla asemptomatik olan bu kitleler erken gebelik döneminde rutin ultrasonografik tarama sayesinde erken dönemde saptanabilmektedir. Büyük çoğunluğu benign olup ilerleyen gebelik haftalarında spontan rezolusyona uğrar ancak persiste eden kitleler hekimi ve hastay takip ve tedavide zorlayabilir. Bu nedenle biz, ilk antenatal vizitte tesadüfen saptanan ve komplike adneksiyel kitle tanisı ile kliniğimize refere edilen hastamızdan yola çıkarak gebelikteki adneksiyel kitlelerin tani, takip ve tedavisini literatur verileriyle irdelemek istedik.

Anahtar kelimeler: Adneksiyel kitle, gebelik.

\section{ABSTRACT}

Adnexial masses during pregnancy which have a wide spectrum treatment from conservative follow -up to complicated surgery have no well established approach algorithm for management. Most of these masses are asymptomatic and thanks to rutin ultrasonography in early pregnancy these lesions can be determined easily. The majority of them are benign and disappear spontaneously as pregnancy grows. But, if the mass persist, it can be challenging for physician and patient in terms of management. For all these reasons, we wanted to review the diagnosis, follow-up and recent treatment options in the light of literature inspired by a case which has reffered to our clinic with the diagnosis of adnexal mass during pregnancy.

Key Words: Adnexal mass, pregnancy.

\section{İletişim Bilgileri:}

Yazışmadan Sorumlu Yazar: Semra KAYATAŞ

Yazışma Adresi: Zeynep Kamil Kadın ve Çocuk Hast.

Eğitim ve Araştırma Hastanesi, İstanbul, Türkiye

E-mail: semrakayatas@gmail.com

Makalenin Geliş Tarihi: 20.10.2013

Makalenin Kabul Tarihi: 01.02.2014

\section{GİRIS}

Gebelikte adneksiyel kitle insidensi 1/81 ila 1/8000 arasında değişmektedir (1). Siklıkla asemptomatik olan bu kitleler erken gebelik döneminde rutin ultrasonografik tarama sayesinde erken dönemde saptanabilmektedir (2). Büyük çoğunluğu benign olup ilerleyen gebelik haftalarında spontan rezolusyona uğrar (3). Ancak persiste eden özellikle büyük kitleler torsiyon, rüptür, kanama veya distosi ile gebeliği komplike hale getirebilir (4). Nadir görülmesine rağmen hekimi ve hastayı takip ve tedavide zorlayan, gözlemsel takipten komplike operasyonlara kadar geniş bir spektrumda tedavi gerektiren gebelikteki adneksiyel kitlelere yaklaşımda belirlenmiş bir konsesusu yoktur. $\mathrm{Bu}$ nedenle biz, ilk antenatal vizitte tesadüfen saptanan ve komplike adneksiyel kitle tanısı ile kliniğimize refere edilen hastamızdan yola ç1karak gebelikteki adneksiyel kitlelerin tanı, takip ve tedavisini literatur verileriyle irdelemek istedik.

\section{OLGU}

29 yaşında, gravida 1 bayan hasta 6 haftalık gebelik ve adneksiyel kitle ön tanısı ile kliniğimize refere edildi. Muayenesinde 6 hafta 1 gün ile uyumlu canlı intrauterin gebelik mevcut olup sol adneksiyel alanda $134 * 106 * 70 \mathrm{~mm}$ boyutlarında içinde yaklașı $30 \mathrm{~mm}$ hiperekojen mural nodul ile uyumlu alan olan ve papiller projeksiyonlar içeren kistik kitle saptandı (Resim 1). Herhangi bir şikayeti olmayan hastanın batın muayenesi rahat idi. Özgeçmişinde bir özelliği olmayıp rutin antenatal tetkikleri normal, Ca 125: 49U/ml idi. Kitlenin ilk planda benign olduğu ve yüksek olasılıkla matür kistik teratom olduğu düşünülerek birinci trimester fetal tarama testinin yapilmasinın ardından ikinci trimesterda elektif şartlarda cerrahi müdahale yapilamasina karar verildi. Ancak hasta 9. gebelik haftasında sol lomber ağrı, bulantı, kusma şikayetileri ile acil polikliniğimize başvurdu. Bilateral alt kadranlarda hassasiyet olan ve tam idrar tahlilinde kalsiyum oksalat kristalleri saptanan hasta hidrasyon ve takip ama- 
cryla interne edildi. Hidrasyona rağmen ağriların devam etmesi, hatta şiddetlenmesi üzerine hastaya frozen eşliğinde laparoskopik kistektomi yapılması planlandı. Uterus ve adneksiyel kistte olası bir yaralanmay engellemek amacıyla Palmer noktasından batına girilerek pünomoperitonyum sağland1. Eksplorasyonda sol overden kaynaklanan $14 * 15 \mathrm{~cm}$ boyutlarında kist olduğu gözlendi (Resim 2), over kendi etrafında 4 kez 360 derece dönmüş torsiyone idi. Kistik mainin batına yayılmasını engellemek için sol alt kadrandan veres iğnesi ile overe girilerek yaklaşık $800 \mathrm{ml}$ mai boșaltıldı (Resim 3 ), ardindan over retorsiyone edildi. Kist bipolar kesici forseps ile total eksize edilerek (Resim 4) endobag ile dıșarı alındı. Frozen sonucu matür kistik teratom ile uyumlu bulundu. Batın yıkama yapılarak işleme son verildi. Postoperatif proflaktik amaçlı progesteron $200 \mathrm{mg}$ vaginal supozutuar 8 saat arayla 48 saat kullanild1. Postoperatif 2. gün ultrasonografide fetal kardiak aktivitenin pozitif olduğu, koryonik membranların intakt olduğu teyid edildikten sonra hasta taburcu edildi. Takiplerinde herhangi bir sorunla karșilașilmayan hastaya 40. haftada oligohidramnios gelişmesi üzerine kür takılarak indüksiyon başlandı. Aktif travayı başlayan hasta anksiyetesinden ötürü doğumu sezaryan ile yapmak istedi. 3600 gr ağırlığında, $50 \mathrm{~cm}$ boyunda canlı kız bebek apgar 1. ve 5. dakikada 9-10 olarak sezaryen ile doğurtuldu.

\section{TARTIŞMA}

Gebelikteki adneksiel kitleler çoğunlukla ilk vizitte yapılan ultrasonografi sayesinde tesadüfen saptanır. Çünkü genellikle asmptomatik olup rüptür, kist içine kanama, enfeksiyon, venöz konjesyon, torsiyon olmadığı sürece sessiz seyreder (5).

Ultrasonografide basit, solid ya da kompleks kistik yapıda görülebilen bu lezyonların gebelikteki en s1k sebebi fonksiyonel kistlerdir. Íkinci trimestere kadar persiste eden korpus luteum kistleri gebelikte görülen tüm kistik adneksiyel kitlelerin \%13-17'i olușturmaktadır (4). Genellikle $5 \mathrm{~cm}$, tek taraflı ve unilokuler kistlerdir. 16-20. gebelik haftasına kadar spontan olarak kaybolurlar. Tüm gebelik dönemleri boyunca görülen adnekisiyel kitleler göz önüne alındığında matür kistik teratom \% 7-37 ve seroz kistadenom \%5-28 insidansla en s1k karşımıza çıkan benign adneksiyel kitlelerdir. Müsinoz kistadenom, endometrioma, hidrosalpenks, heterotopik gebelik, leiomyoma da azalan sıklıkla görülebilir (6). Maligniteler bu kitlelerin yaklaşık \%1-8'inden sorumlu olup özellikle septalı ve duvar kalınlığ $1 \geq 3 \mathrm{~mm}$ olan, asit, papiller projeksiyon, solid komponent içeren düşük impetenslı ve yüksek akım velositeli lezyonlarda akılda tutulmalıdır $(6,7)$. Tümör markerları özellikle ilk trimesterda yükselme

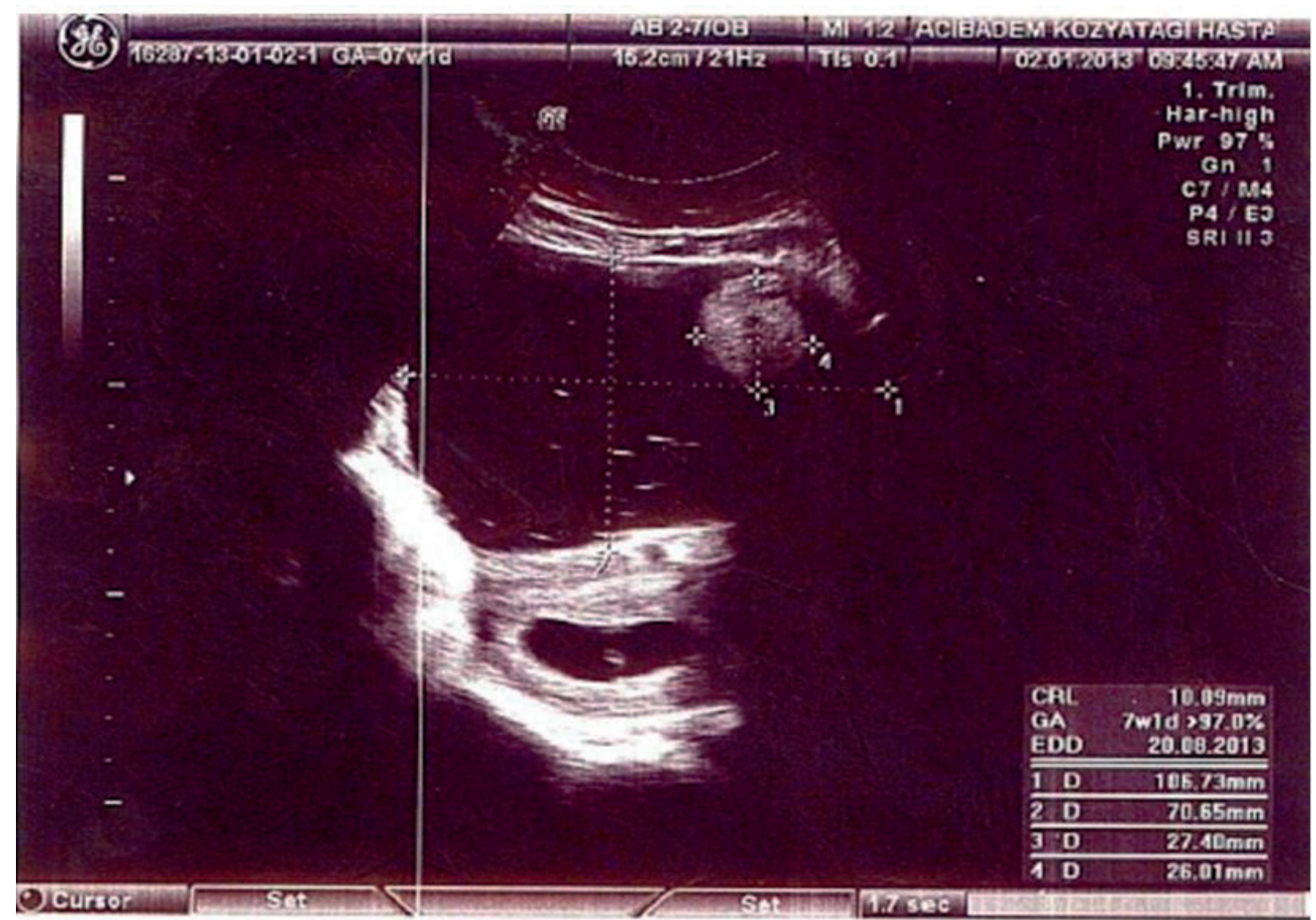

Resim 1: Gebelik kesesi ve kistin aynı kesitte ultrasonografik görüntüsü. 


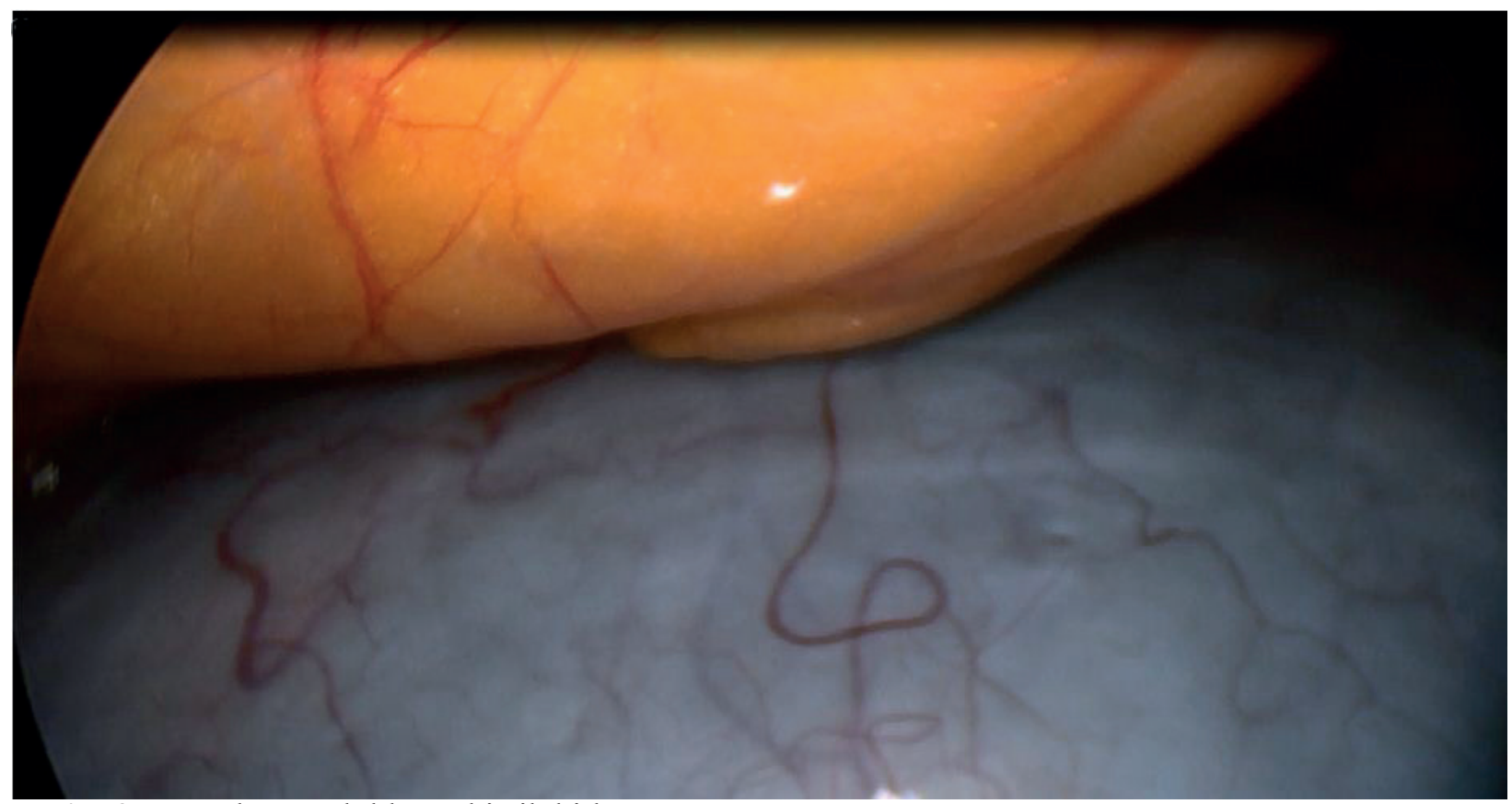

Resim 2: Tüm batını dolduran kistik kitle.

gösterebildiğinden dolayı tanı değeri düşüktür, ancak takip açısından yardımcıdır $(8,9)$. Benign-malign ayırımının net yapılamadığı olgularda, özellikle kitle büyük ise ve orgini sapatanamiyorsa magnetik resonans görüntüleme (MRI), komputorize tomografi (CT) yardımc1 görüntüleme yöntemi olarak kullanılabilir. Ancak CT'de tek bir çekimde anne ve fetus 2-4 radlık radyasyona maruz kaldığı için ve kontrast madde plasentayı geçtiğinden dolayı gebelikte tercih edilmemelidir $(10,11)$.

Hangi hastalara takip hangi hastalara cerrahi müdahale yapılacağına karar verilmesi çoğu zaman zordur. $10 \mathrm{~cm}$ 'den büyük olan kistlerde malignite potansiyeli arttığ 1 için cerrahi yaklaşım uygundur. $5 \mathrm{~cm}$ 'den küçük, asemptomatik kistlerin ise takip edilmesi önerilir. Tabii ki cerrahiyi ertelemek torsiyon, rüptür, distosi, olası bir malignitenin ilerlemesi, tedavinin gecikmesi risklerini de beraberinde taşır. 5-10 $\mathrm{cm}$ arasındaki kitlere yaklaşım ise tartışmalıdır (12-21). Akut abdomen bulguları ile bașvuran torsiyon ya da rüptür şüphesi taşyan hastalara cerrahi yaklaşım kaçınılmazdır. Torsiyon bu kitlelerin en s1k komplikasyonudur (\%10-15) ve genellikle uterusun hızlı büyüdüğü 8-16. gebelik haftalarında görülmektedir (22). Cerrahi müdahele yapılması gerektiğinde anestezik maddelerin olasi fetal olumsuz etkileri hasta ve aile için ankisyeteyi arttırmaktadır. Bu konuda literatür verileri anestezik maddelerin konije-

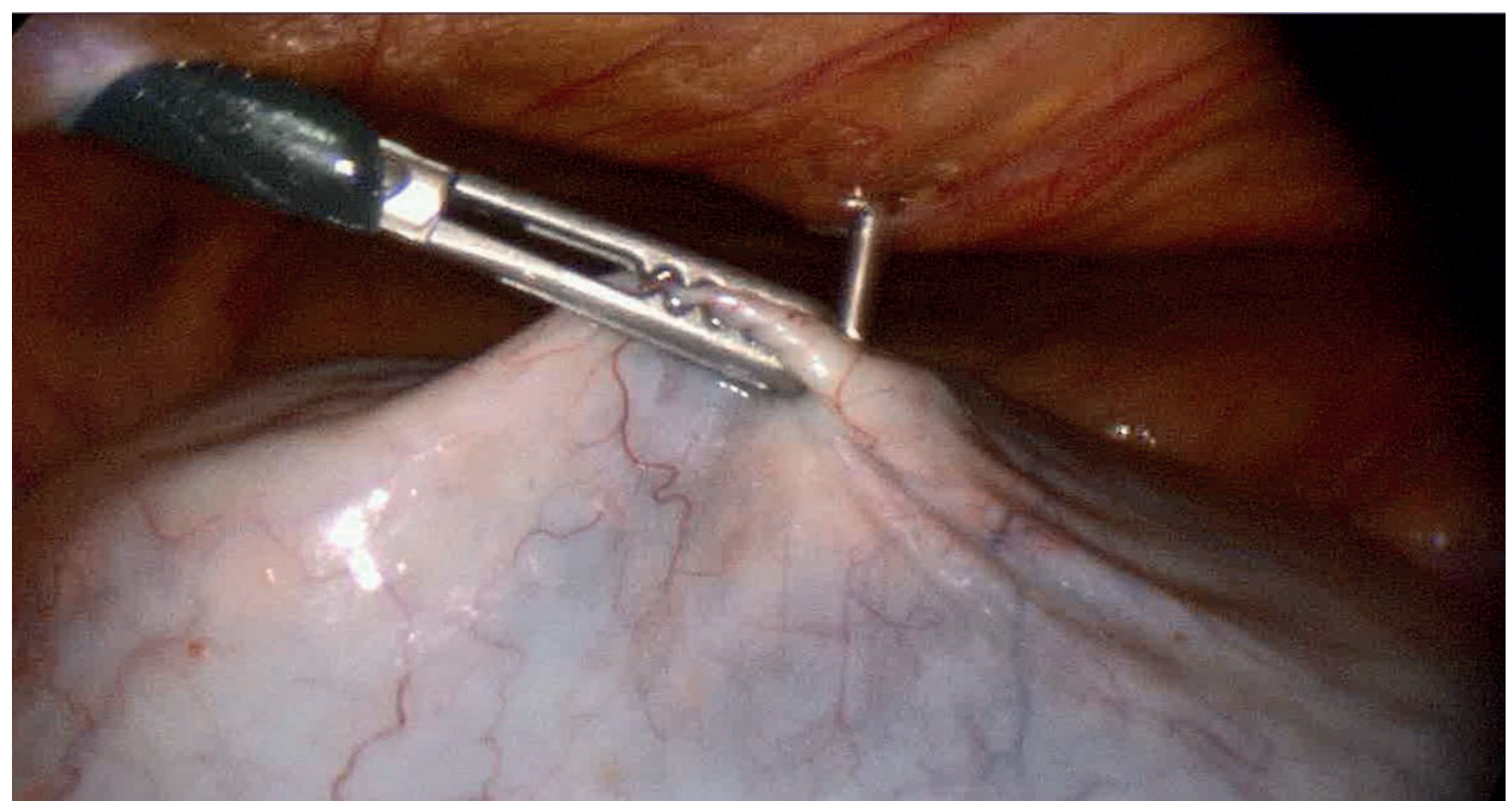

Resim 3: Veres iğnesiyle kiste girilerek aspire edilmesi. 
nital malformasyon ve missed abortusa neden olmadığı ancak düșük doğum ağırlıklı bebeklerden sorumlu olabileceği yönündedir (23). Cerrahiye karar verildiği zaman ise laparatomi mi, yoksa laparoskopi mi yapılacağı sorusu doğar. Tabii ki burada belirleyici olan cerrahın deneyim ve becerisidir. Postoperatif ağrının az olması dolayısıyla analjezik ihtiyacının azalması, perioperatif kanama miktarının az olması, hastanede kalış süresinin kısalığı, enfeksiyon riskinin az olması, hızlı iyileşme ve mobilizasyon, dolayısıyla tromboemboli riskinin az olması gebelikte laparoskopiyi daha cazip kılmaktadır ama acaba gerçekte laparoskopi gebelikete ne kadar güvenlidir?

Yuen ve arkadaşlarının gebelikte adneksiyel kitle nedeniyle laparoskopik cerrahi uygulanan 67 olguluk serisinde, bir vakada operasyondan 6 hafta sonra belirlenebilen bir sebep olmaksızın abort olmuştur (10). Lenglet' in 26 olguluk, Ko'nun 11 olguluk serilerinde laparoskopik müdahale ile ilgili bir komplikasyonla karşılaşılmamıştır $(24,25)$. Soriano ve arkadaşları 454 hastanın laparatomi, 34 hastanın da laparoskopi olduğu retrospektif bir derleme yayınlamıştır. Abort oranları her iki grupta da aynı bulunmuştur ve bu oran her iki grupta da özellikle ilk trimesterde daha yüksek olarak saptanmıştır (26). Reedy ve arkadaşları da laparatomi ve laparoskopi sonuçlarını karşılaştıran çalışmasında İsveç Sağlık Bakanlığı kayıtlarından 20 yıllık süre boyunca laparoskopi yapılan 2181 hasta, laparatomi yapilan 1522 hastanın kayıtlarını incelemişlerdir.

Doğum ağırlığı, estasyonel yaş, intrauterin büyüme geriliği, infant sürvisi ve fetal malformasyon açısından herhangi bir fark gözlemlememişlerdir (27). Günümüzde laparatomi ve laparoskopiyi karşılaştıran, hangi cerrahi yaklaşımın daha üstün olduğunu gösteren prospektif bir çalışma yoktur. Ancak multipl observasyonel çalışma gebelikte adneksiel kitlelere laparoskopik yaklaşımın uygun olduğunu ve gebelikte kontrendike olarak değerlendirilmemesi gerektiğini göstermiştir (28). Tüm bu olumlu sonuçlara rağmen pünomoperitonyumun fetus üzerindeki olası etkileri çelişkiye neden olabilmektedir. Amos ve arkadaşlarının çalıșmasında, laparoskopik cerrahi yapılan 7 gebenin 4'ünde fetal kayıp olduğunu ancak laparotomi grubunda hiçbir fetal kayıpla karşılaşmadıklarını belirtmiştir. Yazarlar maternal karbon dioksit düzeylerinin standart fizyolojik düzeylerde idame ettirilmesine rağmen fetal kayıplarala ilişkili olabileceğini ifade etmiştir $(24,28)$. Karbondioksitin kullanıldığı laproskopi ameliyatlarında artmış inraabdominal basınç, uterin kan akımı- nın azalması, fetomaternal sirkülasyonda hiperkarbi nedeniyla oluşan fetal asidemi intrauterin kayıplara neden olabilir. Bu nedenle gazsız yeni laparoskopi tekniklerine yönelim sözkonusudur (29). İki tel loop sayesinde karın ön duvarının yukarı kaldırıldığ 1 gazsız laparoskopide hem hiperkarbi hem de intraabdominal basınç artış1 engellenerek annenin hemodinamik ve respiratuar sisteminin konvansiyonel laparoskopide görülen olumsuz maternal ve dolayısıyla fetal etkileri önlenmiş olur $(30,31)$. Ayrıca gazsız laparoskopide elektrokoter kullanımının neden olduğu toksik gazlar özellikle karbon monoksid gazı sürekli yüksek basınçlı aspiratör ile emildiğinden fetal teratojenik etki önlenir (32). Amerikan Gastrointestinal ve Endoskopik Cerrahi Birliği 2011 de yayınladığı kılavuzda, laparoskopinin semptomatik overyan kisti olan gebelerde güvenli ve etkili bir tedavi olduğunu belirtmiştir.

Ultrasonografide malignite şüphesi taşımayan, tümor markerları normal olan, kist boyutu $6 \mathrm{~cm}$ olan lezyonlarda öncelikle gözlemsel takip önermiştir (33). Laparoskopik cerrahi müdahele gereken olgularda da eğer aciliyet sözkonusu değilse elektif şartalarda 16-20. gebelik haftalarında operasyonun planlanması, açık Hasson tekniği ile batına girilmesi, trokarların fundusun en az $6 \mathrm{~cm}$ yukarısına veya sol üst kadrana yerleştirilmesini önermiştir (34). Biz de kendi olgumuzda uterusa zarar vermemek ve sol pelvisi tamaman dolduran kistte trokar girişine bağlı rüptür ve peritoneal yayılıma neden olmamak için sol üst kadrandan veres iğnesi ile batına girerek pünomoperitonyumu sağladık. Gebelikte cerrahi müdahale yapılan hastalarda proflaktik tokolitik ajan kullanımının yararlı olduğunu gösteren veri yoktur. Amerikan Gastrointestinal ve Endoskopik Cerrahi Birliği'nin 2011 önerisi de opere edilen gebelerde proflaktik olarak tokolitik ajan kullanılmamasını, tokolizin ancak prematür kontraksiyon gibi haklı obsterik endikasyonları olan hastalara sinırlı tutulmasını önermiştir (33). Yine de çoğunlukla obstetrisyenler olas1 fetal kayıp riskini azaltmak için yan etkisi minimal olan ve gebelikte güvenli olduğu bilinen tokolitik ajanları tercih etmektedir. Biz de hastamiza postoperatif 48 saat süreyle intavaginal progesteron supozutuar kullandık. Aynı şekilde tromboemboli eğiliminin arttığı bu hastalarda proflaktik antikoagulan kullanımı ile ilgili bir k1lavuz da yoktur. Olas1 bir tromboz riskini minimalize etmek için hastamıza perioperatif varis çorabı kullandırdık ve erken mobilizasyon sağladık. Operasyon esnasinda kitlenin malign olduğu saptanırsa tümörün evresi, gestasyonel yaş, grade göz önünde bulundurularak ve ailenin de onayı alınarak te- 


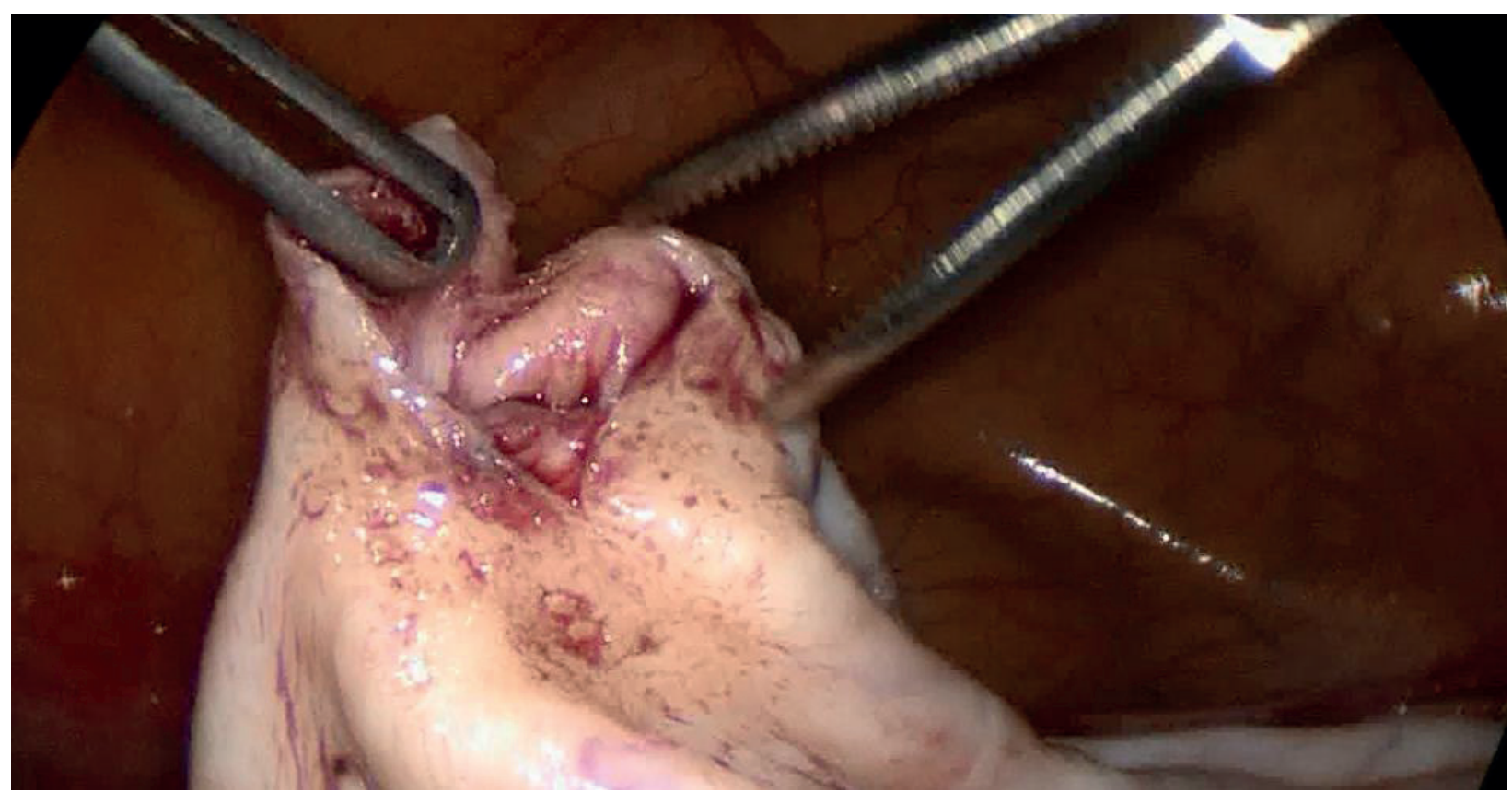

Resim 4: Over yüzeyinin insize edilerek kistektomi yapılması.

davi planlanır. Bazı durumlarda sadece tümörün çıkarılması ve fetal akciğer matürasyonu beklenirken bazı durumlarda akciğer matürasyonu için beklenen dönemde kemoterapi yapilabilir $(24,35)$. İlk trimesterda kullanılan kemoterapotikler fetal malformasyon riski taşırken, ikinci ve üçüncü trimesterde kullanılanlar intrauterin gelişme geriliği, prematürite, düşük doğum ağırlığı, fetal kemik iliği süpresyonuna neden olabilir $(36,37)$. Eğer üçüncü trimesterda tedavi yapilırsa, son kemoterapiden 2-3 hafta sonrasina doğumun planlanması hem maternel hem fetal kemik iliği süpresyonunu engelleyecektir (36).

Gebelikte saptanan adneksiyel kitlelerin çoğu spontan rezolusyona uğrar ve cerrahi müdahale gerekmez. Ultrasonografide basit kistik görünüm, kitle boyutunun $<5 \mathrm{~cm}$ olmas1, 16 . gebelik haftasından önce tanı konması spontan rezolusyon olasılığının yüksek olduğunu düşündürür. Büyük, kompleks kitlelerde rezolusyon olasılığ 1 düşüktür ve neoplastik bir lezyonun göstergesi olabilir. Özellikle persiste eden kitlerde malignite olasılığ 1 arttığ 1 gibi torsiyon, rüptür ve distosi gibi komplikasyonlar da artar.

Sonuç olarak, tanı konduğunda kitle büyüklüğü, gestasyonel yaş, hastanın klinik ve radyolojik muayene bulgularına göre konservatif veya cerrahi yaklaşım seçenekleri değerlendirilir. Asemptomatik, benign olduğu düșünülen adneksial kitlelere öncelikle konservatif yaklaşım tercih edilmelidir ancak müdahale etmek gerekirse ikinci trimester başlangıcında planlanan elektif operasyon hem anne hem fetus açısında en ideal dönemdir.

\section{KAYNAKLAR}

1. Kumarl I, Kaur S, Mohan H, Huri A. Adnexal masses in pregnancy: A 5 year Review.Aust $N Z$ Obstet Gynecol.2006;46:52-4.

2. DePriest PD, deSimone CP. Ultrasound screening in the detection of ovarian cancer. J Clin Oncol.2003;21:194s-9s.

3. Hill LM, et al. The role of ultrasonography in the detection and management of adnexal masses during the second and third trimester of pregnancy. Am J Obstet Gynecol1998;178:703-7.

4. Whitecar P, Turner S, Higby K. Adnexal masses in pregnancy. A review of 130 cases undergoing surgical management. Am J Obstet Gynecol.1999;181:19-24.

5. Yakasai IA, Bappa LA. Diagnosis and management of adnexal masses in pregnancy. $J$ Surg Tech Case Rep.2012 Jul-Dec;4(2):79-85.

6. Bromley B, Benacerraf B. Adnexal masses in pregnancy: Accuracy of sonographic diagnosis and outcome.J Ultrasound Med.1997;16:447-52.

7. Brown DL, Doubilet PM, Miller FH, et al. Benign and malignant ovarian masses: selection of the most discriminating grey-scale and Doppler sonographic features. Radiology 1998;208:103-10.

8. McCarthy A. Miscellaneous medical disorders Dewhurst's textbook of Obstetrics and Gynaecology. 7th ed. United States: Blackwell Publishing;2007,pp.283-8.

9. Aslam N, Ong C, Woelfer B, Nicolaides $K$, et al. Serum CA125 at 11-14 weeks of gestation in women with morphologically normal ovaries. BJOG.2000;107:689-90. 
10. Yuen $P, N g P$, Leung $P$, et al. Outcome of laparoscopicmanagement of persistentadnexal mass during the second trimester of pregnancy. Surg Endosc. 2004;18:1345-7.

11. Wheeler TC, Flesischer AC. Complex adnexal mass in pregnancy predictive value of color doppler sonography.J Ultrasound Med.1997;16:425-8.

12. Fleischer AL, Dimesh MS, Entman SS. Sonographic evaluation of maternal disorders during pregnancy. Radiol Clin North Am. 1990;28:51.

13. Platek DN, Henderson CE, Goldberg GL. The management of a persistemt adnexal mass in pregnancy. Am J Obstet Gynecol.1995;173:1236.

14. Zanetta G, Mariani E, Lisson A. A prospective study of the role of ultrasound in the management of adnexal masses in pregnancy. Br J Obstet Gynacol 2003; 110:578.

15. Hess LW, Peaceman A, O'Brein WF. Adnexal mass occurring with intrauterine pregnancy: Report of fiftyfour patients requiring laparatomy for definitive management. Am J Obstet Gynecol.1988; 158:1029.

16. SoronoD, Yefet Y, Seidman DS. Laparoscopy versus laparatomy in the management of adnexal masses during pregnancy. Fertil Steril.1999;71:955.

17. Benhard LM, Klebba PK, Gray DL, Mutch DG. Prediction of persistence of adnexal masses in pregnancy. Obstet Gynecol.1999;93:585-9.

18. Schemeler KM. Adnexal masses in pregnancy: a review of 130 cases undergoing surgical management. Obstet Gynecol.2005;105:1098-103.

19. Usui R. A retrospective surgery of clinical, pathological and prognostic features of adnexal masses operated during pregnancy. J Obstet Gynecol Res.2008;26:89-93.

20. Koonings PP, Platt LD, Wallece R. Incidental adnexal neoplasms at cesarean section. Obstet $G y$ necol.1988;72:767-9.

21. Nick AM, Schemeler K. Adnexal masses in pregnancy. Perinatology.2010;2:13-21.

22. Usui $R$, Minakami $H$, Kosuge $S$, et al. A retrospective survey of clinical, pathologic and prognostic features of adnexal masses operated ob during pregnancy. J Obstet Gynaecol Res.2000;26:89-93.

23. Mazze RI, Källèn B. Reproductive outcome after anesthesia and operation during pregnancy: a registry study of 5405 cases.Am J Obstet Gynecol1989;161:1178-85.

24. Lenglet Y, Roman H, Robishong B, Bourdel N, at al. Laparoscopic management of ovarian cyst in pregnancy. Gynecol Obstet Fertil.2006;34:101-6.
25. Ko ML, Lai T, Chen S. Laparoscopic management of complicated adnexal masses in the first trimester of pregnancy. Fertil Steril.2009;52:327-34.

26. Soriano D, Yuval Y, Saidman D, Goldenberg M, et al. Laparoscopy versus laparatomy in the management of adnexal masses in pregnancy. Fertil Steril. 1999;71:955-60.

27. Reedy M, Kallen B, Kuehl T. Laparoscopy during pregnancy: a study of five fetal outcome parameters, with use of Swedish Health Registry. Am Obstet Gynecol.1997;177:673-80.

28. Amos J, Schorr S, Norman P, et al. Laparoscopic surgery during pregnancy. Am J Surg. 1996; 171:435-7.

29. Bunyavejchevin S, Phupong $V$. Laparoscopic surgery for presumed benign ovarian tumor during pregnancy. Cochrane Database of Systematic Reviews2013,Issue1. Art.No.:CD005459. dor:10.1002/14651858.cd005459.pub3.

30. Akira S, Yamanaka A, Ishihara T, Takeshita T, Araki T. Gasless laparoscopic ovarian cystectomy during pregnancy: comparison with laparotomy. Am J Obstet Gynecol 1999;180:554-7.

31. Tanaka H, Futamura N, Takubo S, Toyoda N. Gasless laparoscopy under epidural anesthesia for adnexal cysts during pregnancy. J Reprod Med 1999;44:929-32.

32. Beebe DS, Swica H, Carlson N, Palahniuk $R J$, Goodale RL. High levels of carbon monoxide are produced by electro-cautery of tissue during laparoscopic cholecystectomy. Anesth Analg 1993;77:338-41.

33. Guidelines for diagnosis, treatment and use of laparoscopy for surgical problems in pregnancy. Los Angeles(CA): Society of American Gastrointestinal and Endoscopic Surgeons(SAGES);2011.

34. Guidelines Committee of the Society of American Gastrointestinal and Endoscopic Surgeons. Yumi H. Guidelines for diagnosis, treatment and use of laparoscopy for surgical problems in pregnancy. Surg Endosc.2000; 10:511-5.

35. Schemeler K, William W, Jeffrey PF, et al. Adnexal massesin pregnancy: Surgery compared with observation. Obstet Gynecol.2005;105:1098-103.

36. Backes CH,Moorehead PA, Nelin LD. Cancer in pregnancy: fetal and neonatal outcomes. Clin Obstet Gynecol 2011;54:574-90.

37. Brewer $M$, Keuck A, Runowicz CD. Chemotherapy in pregnancy. Clin Obstet Gynecol 2011;54:602-18. 